\title{
A Study on Laparoscopy in The Diagnosis Of Chronic Abdominal Conditions
}

\author{
Dr.P.Ganesh Ms, Fmas,Fiages ${ }^{1}$, \\ ${ }^{1}$ Associate Professor Of Surgery \\ Govt Theni Medical College,Theni \\ tamilnadu, India.
}

\author{
Dr.K.Kannan $\mathrm{Ms}^{2}$ \\ Assistant Professor Of Surgery \\ 2 Govt Theni Medical College, Tamilnadu \\ india
}

\section{Introduction}

Many surgeons have had the challenging experience of facing an unsolvable chronic abdominal pain and with uncertain diagnosis or staging of intra abdominal tumours. History taking, physical examinations, biochemical tests \& sequences of advanced noninvasive imaging studies might provide some help but are often insufficient for an accurate diagnosis. Imaging studies cannot provide an accurate diagnosis of the aforementioned chronic abdominal conditions. Nevertheless exploratory laparotomy has inevitably Hence Diagnostic Laparoscopy is indicated in any situations when inspection of abdomino-pelvic organs will help to establish a diagnosis and for further subsequent management. Diagnostic laparoscopy is a minimally invasive surgical procedure that allows the visual examination and documentation of intra abdominal organs in order to detect any pathology. Elective diagnostic laparoscopy refers to the use of the procedure in chronic intra abdominal disorders. Diagnostic laparoscopy is safe, well tolerated and can be performed in an inpatient setting under general anaesthesia. Diagnostic laparoscopy in addition to giving a definitive diagnosis reduces the operating time, postoperative morbidity and hospital stay. Hence it is cost effective.

\section{Aims Of The Study}

To make a definitive diagnosis \& to know the exact pathology not imaged by other modalities.

To assess the extent of the disease.

To avoid unnecessary non therapeutic laparotomies.

To confirm the clinical and radiological findings in doubtful cases.

To give effective relief to the patient wherever possible.

\section{Indications:}

\section{Benign:}

Diagnostic Laparoscopy has been used in both benign and malignant Conditions.

a) Acute abdominal pain:

Intestinal ischemia, Bowel obstruction, Perforated viscus, Acute right lower quadrant pain due to gastro intestinal and gynaecological causes.

b) Chronic abdominal pain:

Post operative adhesions,Abdominal tuberculosis, Mesenteric adenitis, Appendicial abnormalities, Fitz-

Hugh-Curtis syndrome, Hernia, Endometrosis, Ovarian abnormalities and malignancy

c) Infertility

d) Blunt or penetrating abdominal trauma

e) Liver disease and Ascites.Malignant:

a) Stage intra-abdominal malignancy:

Oesophageal, Gastric, Peripancreatic, Hepatic (primary and secondary)

Colonic,Ovarian,Lymphoma

b) Neo-adjuvant and adjuvant therapies/obtain tissue for diagnosis. 


\begin{tabular}{|l|l|}
\hline \multicolumn{2}{|l}{ Contraindications for diagnostic laparoscopy } \\
\hline $\begin{array}{l}\text { Absolute } \\
\text { Contraindications : }\end{array}$ & $\begin{array}{l}\text { Known Diaphragmatic hernia. } \\
\text { Hemodynamic instability. }\end{array}$ \\
\hline $\begin{array}{l}\text { Relative } \\
\text { Contraindications: }\end{array}$ & \\
\hline Contraindications: & Possible Risk: \\
\hline Previous Surgery & Adhesions leading to visceral injuries. \\
\hline Intra-abdominal sepsis & Friable bowel prone to injury \\
\hline Bowel Obstruction & Friable bowel prone to injury \\
\hline Morbid Obesity & $\begin{array}{l}\text { Difficult access, requirement for longer instruments, } \\
\text { increased intra abdominal pressure. }\end{array}$ \\
\hline Pregnancy & \begin{tabular}{l} 
Injury to gravid uterus \\
Vascular injury. \\
\hline Aneurysmal disease
\end{tabular} \\
\hline $\begin{array}{l}\text { Raised intrabdominal pressure may significantly } \\
\text { reduce the cardiac preload. Carbon dioxide } \\
\text { insufflation may result in Carbon dioxide retention. }\end{array}$ \\
\hline Cardio-pulmonary \\
\hline
\end{tabular}

\section{Materials And Methods}

1. Patients subjected to this study were taken from surgical unit of Government theni medical college theni tamilnaduiover a period of 4months from January 2017toapril 2017

2. 60 patients underwent diagnostic laparoscopy (24 males and 36 females) for chronic abdominal symptoms.

3. Factors such as age, sex, previous surgery, duration of pain, and number of attacks were taken into account.

4. Patients were investigated with Complete blood count, blood sugar, renal function test, Liver function test, ultra sonogram and computed tomography of abdomen and pelvis.

5. Diagnostic laparoscopy was performed under general anesthesia by trained surgeons.

6. Biopsy specimen were subjected to Histopathological examination.

7. Ascitic fluid sent for biochemical examination and cytology. Pus from abscess cavities was sent for microbiological examination.

\section{Consent:}

Individual written and informed consent obtained from all 60 patients enrolled in the study.

\section{Inclusion criteria:}

1. Chronic Abdominal pain

2. Vague Abdominal mass

3. Intraabdominal Lymphadenopathy of unknown etiology

4. Ascites of unknown etiology

5. Surgical Jaundice

6. Subacute Intestinal obstruction

7. Miscellaneous conditions.

\section{Exclusion criteria :}

1. Generalised peritonitis

2. Abdominal wall infections

3. Mechanical or paralytic ileus

4. Severe cardiopulmonary disease

5. Coagulopathy

6. Pregnancy

7. Patient unfit for General Anaesthesia

\section{Observation Of The Study}

The total number of cases studied is 60 which included 36 female and 24 male patients. The patients were attending the surgical outpatients department of govt theni medical college,theni,tamilnadu. Among 36 female cases, the common age groups presented with chronic abdominal symptoms were between 31-40 years and among 24 male cases, were between 31 - 40 years.

The incidence of chronic abdominal pain in different age groups is shown in table below 


\begin{tabular}{|c|c|c|}
\hline Age in years & Females & Males \\
\hline $15-20$ & 4 & 2 \\
\hline $21-30$ & 8 & 6 \\
\hline $31-40$ & 13 & 9 \\
\hline $41-50$ & 6 & 4 \\
\hline $51-60$ & 3 & 2 \\
\hline$>60$ & 2 & 1 \\
\hline
\end{tabular}

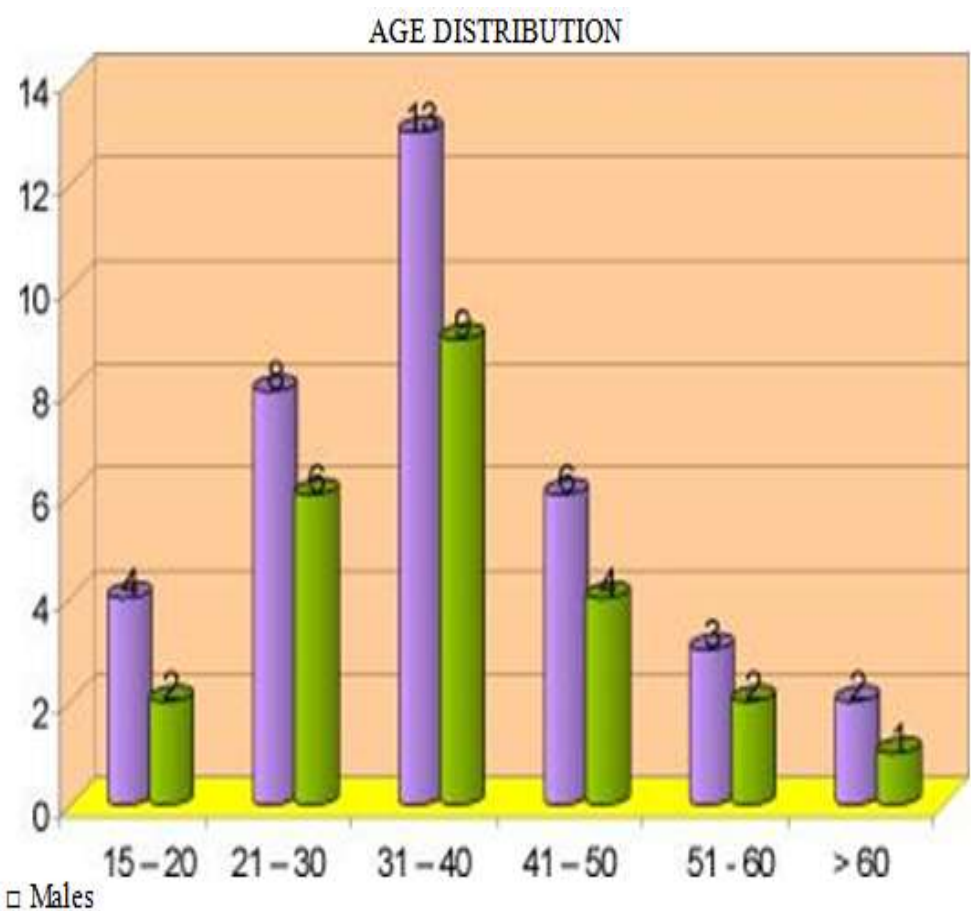

From the study, the commonest cause of admission for chronic abdominal conditions in females were found to be due to post-operative adhesions followed by chronic appendicitis and Tuberculous abdomen, whereas in males commonest cause were Tuberculous abdomen, Chronic appendicitis and others as in Table given below.Etiology of admission for chronic abdominal conditions in females

\section{ETIOLOGY - FEMALE}
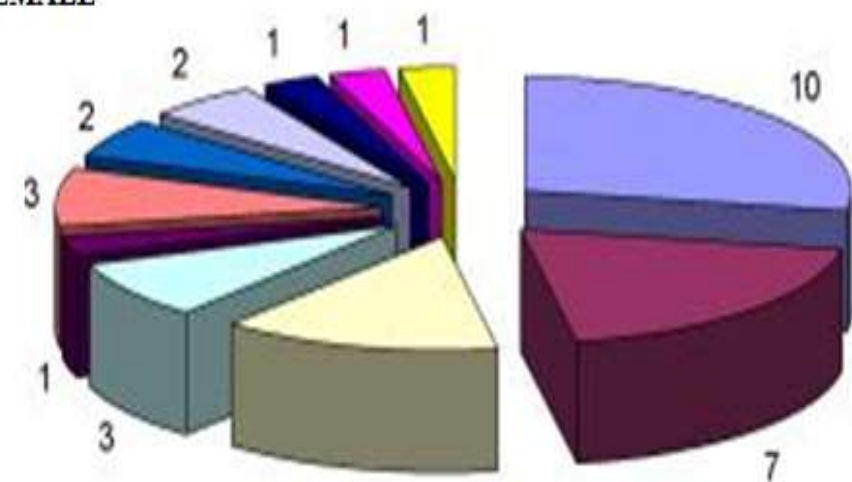
5

\begin{tabular}{|ll|}
\hline Post-operative adhesions & —Chronic appendicitis \\
$\square$ Tuberculous Abdomen & $\square$ Mesenteric adenitis \\
- Malignancy & $\square$ Pelvic inflammatory disease \\
$\square$ Ovarian cyst & $\square$ Endometriosis \\
$\square$ Pelvic Abscess & —Cirrhosis \\
$\square$ Secondary deposits over peritoneum & \\
\hline
\end{tabular}

Etiology of admission for chronic abdominal conditions in males

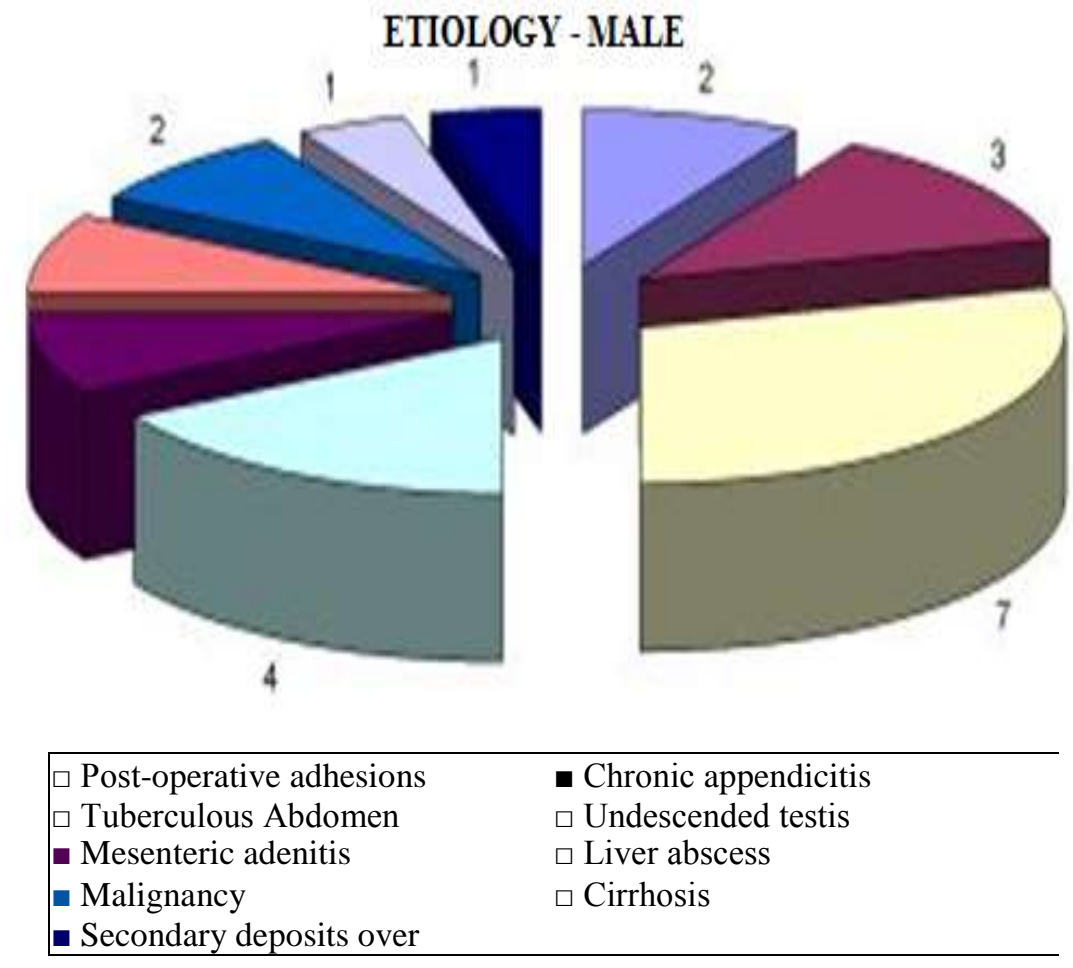

\section{Discussion Of The Study}

In the study of diagnostic laparoscopy in 60 cases of chronic abdominal conditions, in females (36 cases) 10 cases presented with chronic abdominal pain due to post-operative adhesions, of those 5 cases were due to previous caesarian section 3 cases were due to previous abdominal surgeries, 2 cases were due to sterilisation. In males(24 cases), 2 cases presented with pain due to previous abdominal surgery. Out of these 12 cases after adhesiolysis, 10 cases showed were pain free, while 2 cases had persistent pain postoperatively. These 2 cases on regular follow up showed improvement with conservative management.Abdominal tuberculosis was found in 12 cases, 5 females and 7 males in the average age group of 20 - 30 years. Peritoneal tuberculosis was found in 9 cases, Ileocecal tuberculosis in 3 cases. Peritoneal biopsy was taken and sent for histopathological examination which revealed tuberculosis. Ascitic fluid analysis done for 2 cases. ATT was instituted for all the 12 cases and they responded well.Chronic Appendicitis was found in 10 cases, in 7 females and in 3 males for which appendicectomy was done. On review, 9 cases were symptom free, 1 case had persistent pain managed conservatively.Mesenteric adenitis was found in 5 cases, 3 females and 2 males, in which no other significant laparoscopic findings were seen.In females, Pelvic Inflammatory Disease was seen in 3 cases, Ovarian cyst in 2cases and Endometriosis in 2cases which were managed accordingly.In males, undescended testis was seen in 4 cases for which laparoscopic orchidectomy was done.Pelvic abscess was seen in 1 female case. Laparoscopic drainage was done. Treated with Antibiotics depending on microbiologic report of pus culture and sensitivity.

Cirrhosis was present in 1 male and 1 female patient and were under physician follow up. Secondary deposits over peritoneum was seen in 2cases for which laparoscopic peritoneal biopsy was taken and sent for HPE.Among 60 cases, 3 cases showed malignancy, 2 in male and 1 in female patients. They were secondaries liver and Hepatocellular carcinoma. They were assessed for operability and managed accordingly. Liver abscess were seen in 2 male patients for which laparoscopic abscess drainage was done.Patient who underwent 
diagnostic laparoscopy stayed in hospital for 3 days on an average, and were discharged uneventfully.Among 60 cases, 2 cases had port site infection and no other complications were seen.

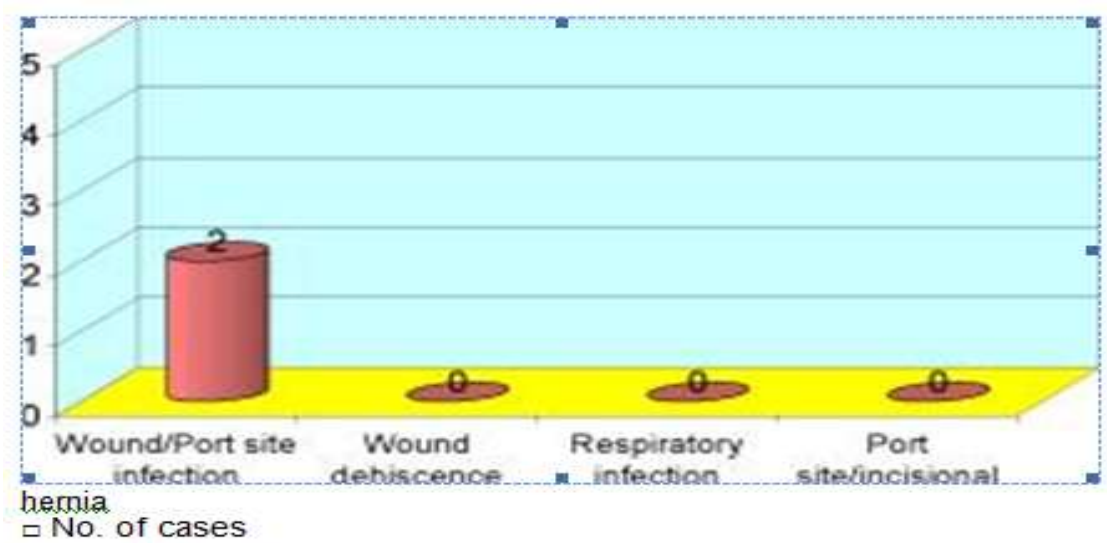

With the increasing popularity of laparoscopy, more patients with chronic abdominal pain are undergoing diagnostic laparoscopy and adhesiolysis. Several studies showed $80 \%$ improvement in pain after adhesiolysis. These studies suggest that adhesion related chronic abdominal pain appears to be much more common than what most surgeons appreciate. Results of laparoscopic adhesiolysis for chronic abdominal pain

In a review of 388 patients with abdominal adhesions, $79 \%$ had a history of surgery, $18 \%$ had a history of peritoneal infection and $11 \%$ had congenital adhesions.A collective analysis of 6 series howed that $36 \%$ patients (680 of 1897) presenting with post operative adhesional intestinal obstruction had undergone appendicectomy. In women, the commonest cause of post operative adhesive intestinal obstruction is previous hysterectomy. Dr.C.Palanivelu's study on abdominal tuberculosis shows in 230 cases, there were 132 males and 98 females. Average age being 52 years.

Peritoneal tuberculosis cases were treated by diagnostic laparoscopy and peritoneal biopsy, followed by Anti-tuberculous therapy. Out of 83 cases of ileocecal tuberculosis, 63(27.3\%) cases had intestinal obstruction and underwent limited laparoscopic resection with primary anastomosisfollowed by ATT. The other 20(9\%) were treated with diagnostic laparoscopy with biopsy and ATT.

In chronic appendicitis, evaluation with ultrasonogram is operator dependent. However, it is frequently unable to visualize normal appendix. A recent metanalysis of 14 prospective studies showed Ultrasound to have sensitivity of 0.86 and specificity of 0.81 . Computed Tomography metaanalysis of 12 prospective studies showed sensitivity of 0.94 and specificity of 0.95 . Accuracy of Computed tomography and ultrasound for diagnosis of appendicitis

Diagnostic laparoscopy has a sensitivity and specificity of $100 \%$ as evidenced by many studies.

\section{Conclusion}

The study was successfully completed and diagnostic laparoscopy was proved successful in diagnosing chronic abdominal conditions in $100 \%$ cases out of which $56.25 \%$ was therapeutic too. The study revealed that diagnostic laparoscopy can safely be used when other investigatory modalities fail to clinch the diagnosis. Diagnostic laparoscopy continues to have a place in the diagnostic armamentarium, preventing unnecessary exploration for those patients who would not benefit and not precluding an open procedure from those who gain from it. It is a great comfort to the patient since it avoids unnecessary investigations and procedure 


\section{LAPAROSCOPIC ADHESIOLYSIS}

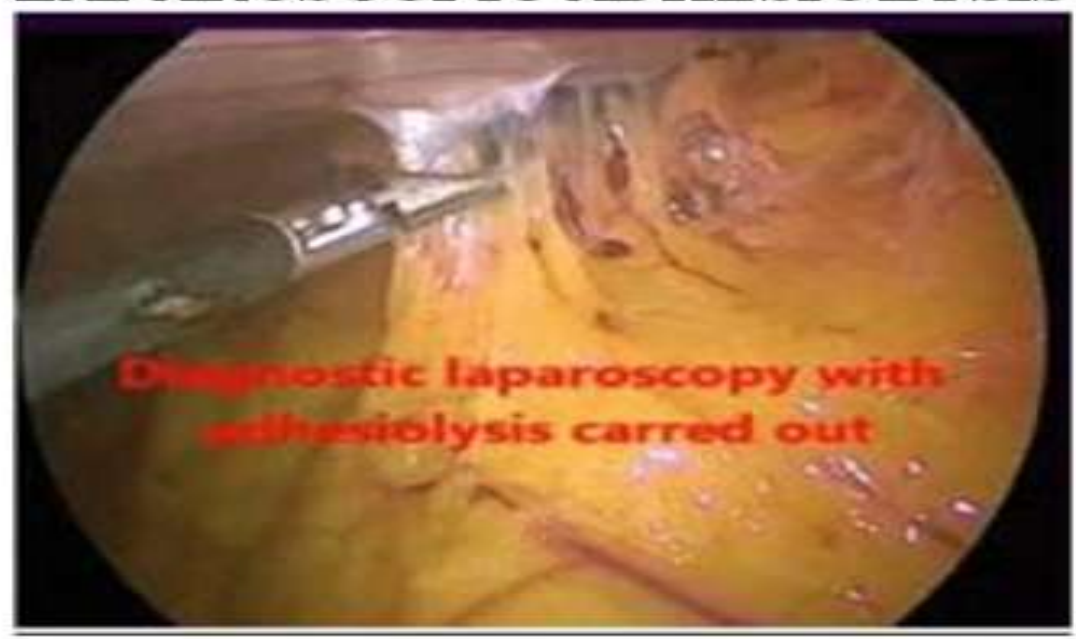

Laparoscopy Showing Abdominal Tuberculosis 


\section{MESENTERIC ADENITIS}

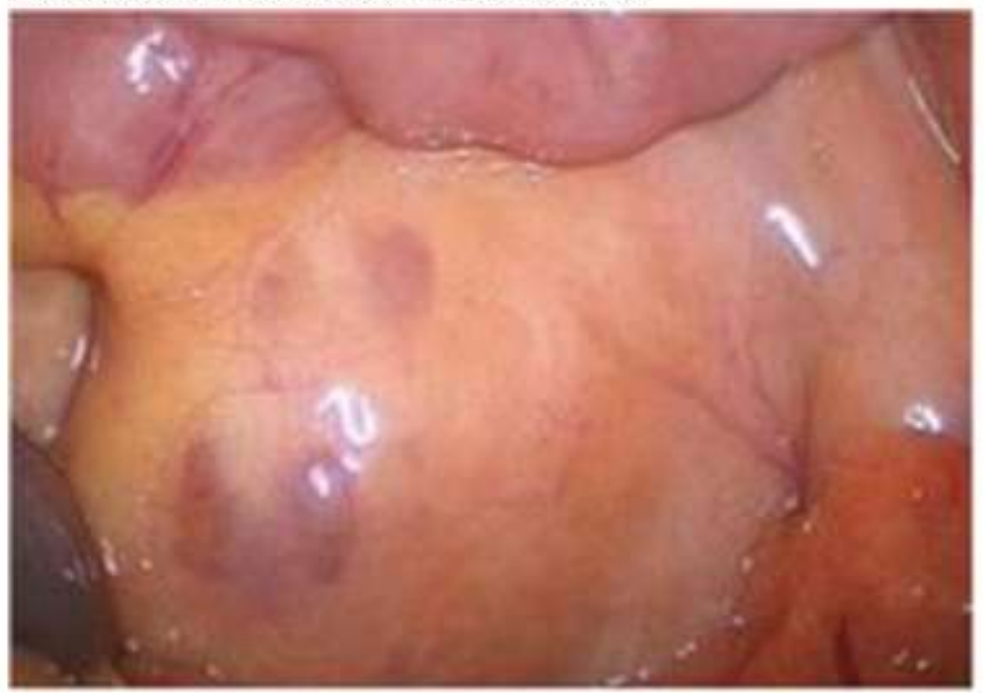

LAPAROSCQPIC VIEW OF INTRAABDOMINAL TESTIS 


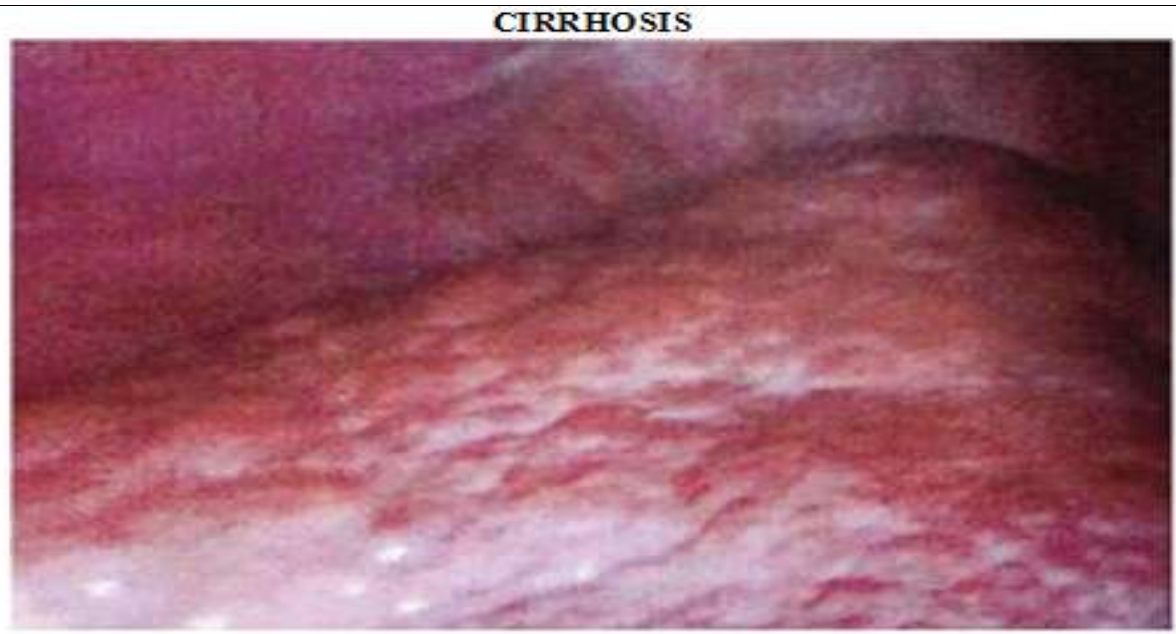

LAPAROSCOPIC BIOPSY 'OF LIVER MALIGNANCY

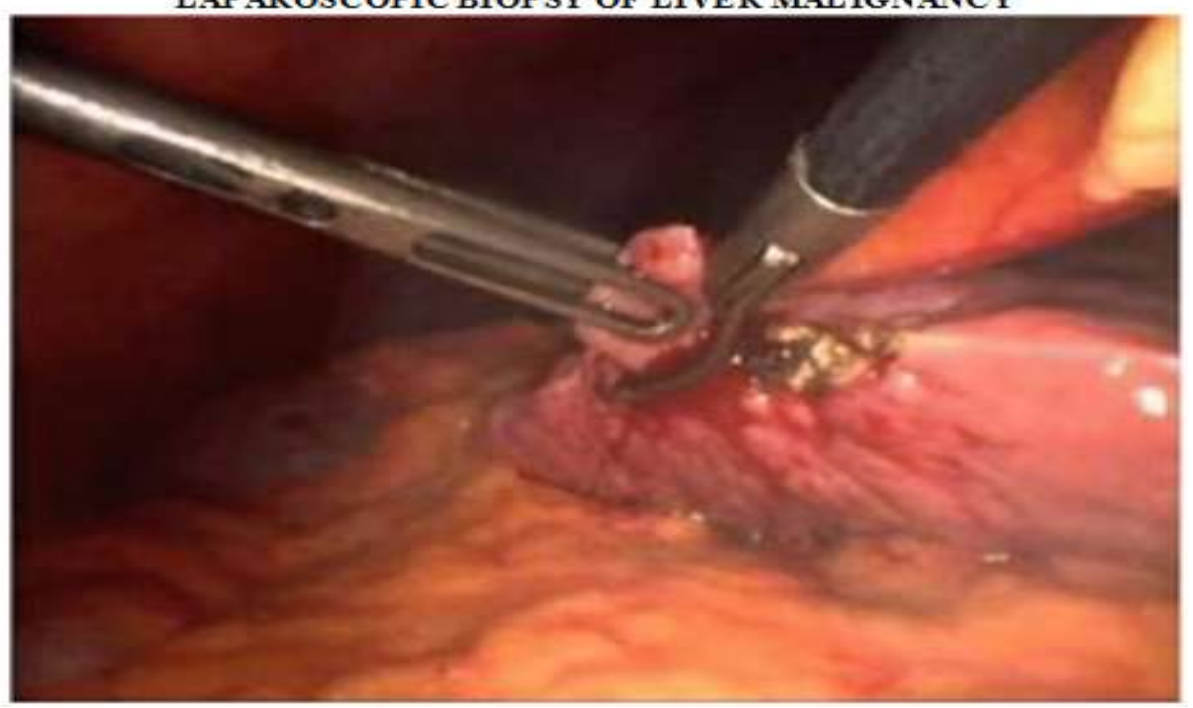

Bibliography

[1]. Husain M, Sachan PK, Khan S, Lama L, Khan RN. Role of diagnostic laparoscopy in chronic and recurrent abdominal pain, Trop Gastroenterol. 2013 JulSep;34(3): 1703.

[2]. Amandeep S Nar, Ashvind Bawa, Atul Mishra, and Amit Mittal, Role of Diagnostic Laparoscopy in Chronic Abdominal Conditions with uncertain diagnosis, Niger J Surg. 2014, Jul Dec; 20 (2): 75-78

[3]. Gouda M Ellabban and Emad N Hokkam, The efficacy of laparoscopy in the diagnosis and management of chronic abdominal pain, Journal of Minimal Access Surgery, 2010 Oct Dec : 6(4) : 95-99

[4]. Kinnaresh Ashwin Kumar Baria, Role of Laparoscopy in diagnosis and management of Chronic abdominal pain, Indian J.Sci.Res. $4(1): 65-68,2013$

[5]. Laparoscopic lysis of adhesions, World J Surg 2006 Apr; 30 (4): 535 - 40

[6]. Bonjer $\mathrm{Hj}$; Hazebroek E.J. Kazemier Giufffida M.C. Meijer. W.S, Lange.J.F., Open Versus Closed establishment of Pneumoperitoneum in laparoscopic surgery, British Journal of surgery. Volume 84 , Number 5, May 1997, PP 599-602 (4).

[7]. Pawan Lai, Lakhvinder Singh, Agarwal and Ravi Kant, Open Port Placement of the First Laparoscopic Port: A Safe Technique, Journal of the Society of Laproendoscopic surgeons, JSLS. 2004 OctDec; 8(4): 364- 366.

[8]. Josef. E. Fischer, Fischer's Mastery of Surgery, $5^{\text {th }}$ edition, 251-258. Norman. S. Williams, Christopher J.K. bulstrode \& P. Ronan O'Connell, Bailey and Love's, Short Practice of Surgery, $26^{\text {th }}$ edition, 93-95

[9]. Michael J. Zinner, Stanley W. Ashley, Maningot's Abdominal operations, $12^{\text {th }}$ edition, 63-67

[10]. F. Charles Brunicardi, Dana. K. Andersen, Timothy. R.Billion, David L. Dunn, John G. Hunter, Jeffrey B. Mathews, Raphael E.Pollock, Schwartz's Principles of Surgery, $9^{\text {th }}$ edition, 681-683

[11]. Sriram Bhat. M, SRB's Manual of Surgery, $4^{\text {th }}$ edition, 1267-1270.

[12]. Zaffar K Sayedl, Radha A Verma2, Kumar Premjeet Madhukar3, Amogh R Vaishampayan3, Mugdha S Kowlil, Chirag Vaja, Role of Diagnostic Laparoscopy in Chronic Abdominal Pain, International Journal of Scientifi c Study | July 2015 | Vol 3 | Issue 4

[13]. Sachin Jamma and Ashish Badkal, Study of role of laparoscopy in chronic abdomen, International Journal of Biomedical and Advance Research 2015; 6(07): 518-521. 
[14]. B.D Dhaigude Abhishek Bhushan Abhishek Kumar Singh, Bahul Vakaria Prithviraj Patil Shilpi Shree, Therapeutic Role of Diagnostic Laparoscopy In Chronic Abdominal Pain, Indian Journal Of Applied Research, Volume : 6 | Issue : 4 | April 2016 | ISSN - 2249-555X | IF : 3.919 | IC Value : 74.50

[15]. Art of Laparoscope surgery volume : 2,Dr.C.Palanivelu chapter 58. PageArt of Laparoscopic surgery volume : 1 , Dr.C Palanivelu page 11 - 83 , Page 153 - 177.

[16]. Campbell's urology. $8^{\text {th }}$ edition volume : 3. page 2374 to 2378 .

[17]. Atlas of Laparoscopic surgery - Garth . H.Balantyne page 2 - 9.

[18]. Text of Laparoscopy Hulka and Reich. $3^{\text {rc } *}$ edition 491- 496, Page $411-415$

[19]. Atlas of Laparoscopic surgical technique, Darzi,Talamine,C.Dunn Page 83 - 86

[20]. Shackfield's surgery of the Alimentary tract volume $1 \&$ volume 2. page2141,2152,1640 \& 1656

[21]. Nagy AG, James D. : Diagnostic laparoscopy.Am J .surg 1989: 157 :

[22]. $490-494$

[23]. Guidelines for diagnostic laparoscopy . Society of American Gastro intestinal Endoscopic surgeons(SAGES).Surg.Endoscopy 1993 ; 7(4) : 367-368

[24]. Shayani V, Siegert C, Favia P.: The role of laparoscopic ahesiolysis in the treatment of patients with chronic abdominal pain or recurrent bowel obstruction. J Soc Laparoendosc Surg. 2002 Apr - Jun ; 6(2): 111 - 